\title{
Electrical Brain Stimulation and Continuous Behavioral State Tracking in Ambulatory Humans
}

\author{
Filip Mivalt ${ }^{1,2+}$, Vaclav Kremen $^{1,3^{*}+}$, Vladimir Sladky ${ }^{1,4,5}$, Irena Balzekas ${ }^{1,6,7}$, Petr Nejedly ${ }^{1,8}$, Nick Gregg ${ }^{1}$, Brian \\ Lundstrom $^{1}$, Kamila Lepkova ${ }^{4}$, Tereza Pridalova ${ }^{1,2,5}$, Benjamin H. Brinkmann ${ }^{1,9}$, Pavel Jurak ${ }^{8}$, Jamie J. Van \\ Gompel $^{11}$, Kai Miller ${ }^{11}$, Timothy Denison ${ }^{10}$, Erik St Louis ${ }^{12}$, and Gregory A. Worrell ${ }^{1,9}$ * \\ ${ }^{1}$ Bioelectronics Neurophysiology and Engineering Laboratory, Department of Neurology, Mayo Clinic, Rochester, MN, USA. \\ ${ }^{2}$ Department of Biomedical Engineering, Faculty of Electrical Engineering and Communication, Brno University of Technology, Brno, \\ Czechia. \\ ${ }^{3}$ Czech Institute of Informatics, Robotics, and Cybernetics, Czech Technical University in Prague, Prague, Czech Republic. \\ ${ }^{4}$ Faculty of Biomedical Engineering, Czech Technical University in Prague, Kladno, Czech Republic. \\ ${ }^{5}$ International Clinical Research Center, St. Anne's University Hospital, Brno, Czech Republic. \\ ${ }^{6}$ Mayo Clinic School of Medicine and the Mayo Clinic Medical Scientist Training Program, Rochester, MN, USA. \\ ${ }^{7}$ Biomedical Engineering and Physiology Graduate Program, Mayo Clinic Graduate School of Biomedical Sciences, Rochester, MN, USA. \\ ${ }^{8}$ The Czech Academy of Sciences, Institute of Scientific Instruments, Brno, Czech Republic. \\ ${ }^{9}$ Department of Physiology and Biomedical Engineering, Mayo Clinic, Rochester, MN, USA. \\ ${ }^{10}$ Department of Biomedical Engineering, Oxford University, Oxford, UK. \\ ${ }^{11}$ Department of Neurosurgery, Mayo Clinic, Rochester, MN, USA. \\ ${ }^{12}$ Center for Sleep Medicine, Departments of Neurology and Medicine, Divisions of Sleep Neurology \& Pulmonary and Critical Care \\ Medicine, Mayo Clinic, Rochester, MN. \\ + co-first authors \\ * Corresponding authors

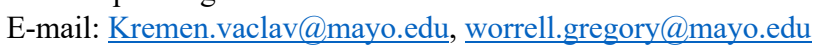

\begin{abstract}
Electrical brain stimulation (EBS) is an established treatment for patients with drug-resistant epilepsy. Sleep disorders are common in people with epilepsy and EBS therapies may actually further disturb normal sleep patterns and sleep quality. Novel devices capable of EBS and continuous intracranial EEG (iEEG) telemetry enable detailed assessments of therapy efficacy and tracking of sleep and comorbidities. Here, we investigate the feasibility of automated sleep classification using continuous iEEG data recorded from Papez's circuit in four patients with drug resistant mesial temporal lobe epilepsy using an investigational implantable sensing and stimulation device with electrodes implanted in bilateral hippocampus (HPC) and anterior nucleus of thalamus (ANT). The iEEG recorded from HPC are used to classify sleep during concurent ANT stimulation. Simultaneous polysomnography and HPC sensing was were used to train, validate and test an automated classifier for a range of ANT EBS frequencies $(2 \mathrm{~Hz}, 7 \mathrm{~Hz}, 100 \mathrm{~Hz}$, and $145 \mathrm{~Hz})$. We show that it is possible to build a patient specific automated sleep staging classifier using power in band features extracted from one HPC sensing channel. The patient specific classifiers performed well under all thalamic EBS frequencies with an average F1-score 0.894, and provided viable classification into major sleep categories (Awake, NREM, REM). Within this project, we retrospectively analyzed classification performance with gold-standard polysomnography annotations, and then prospectively deployed the classifier on chronic continuous iEEG data spanning multiple months to characterize sleep patterns in ambulatory patients living in their home environment. The ability to continuously track behavioral state and fully characterize sleep should prove useful for optimizing EBS for epilepsy and associated sleep, cognitive and mood comorbidities.
\end{abstract}

Keywords: Electrical Brain Stimulation, Implantable Devices, Automated Sleep Scoring, Epilepsy 
medRxiv preprint doi: https://doi.org/10.1101/2021.08.10.21261645; this version posted August 12, 2021. The copyright holder for this

preprint (which was not certified by peer review) is the author/funder, who has granted medRxiv a license to display the preprint in perpetuity.

All rights reserved. No reuse allowed without permission.

\section{Introduction}

Electrical brain stimulation (EBS) is an established therapy for drug-resistant focal epilepsy [1-4], but the effects of EBS on sleep are poorly understood. A small study of responsive neurostimulation (RNS) with only hippocampal or cortical stimulation did not find evidence for sleep disruption [5], but thalamic EBS has been reported to cause sleep disruption [6].

With the high prevalence of sleep disturbances in people with epilepsy (PWE) [7-12], and the potential for seizures to follow sleep related circadian patterns [13-16], the precise impact of EBS on sleep is of significant clinical importance. Morevoer, sleep is known to play an important role in the cognitive $[8,17]$ and mood $[18,19]$ comorbidities of epilepsy. Unfortunately, objectively assessing sleep in patients undergoing EBS has been difficult due to the absence of longitudial data and the unreliability of patient sleep self reporting [20]. A quantiative assessment of sleep architecture using ambulatory iEEG data in patients with epilepsy allows investigation of long-term behavioral state dynamics and the complex interplay of epilepsy, sleep and EBS that should ultimately increase the precision of adaptive EBS [21].

Although clinical gold standard polysomnography involves trained experts reviewing scalp EEG recordings, prior research has shown the feasibility of automated behavioral state classification utilizing invasively recorded iEEG signals. These studies demonstrated the feasibility of classification of wakefulness and non-Rapid-Eye-Movement (NREM: N2 \& N3) sleep stages [22-25]. However, the feasibility of REM classification and the impact of EBS induced iEEG artifacts on automated sleep scoring remains unclear.

Our understanding of the chronic effects of EBS on sleep has been limited by the recording capabilities of current EBS devices [26-28]. Recent advances in EBS devices have included rechargeable batteries that support the energy demands of continuous iEEG data telemetry. One such system, the investigational Medtronic Summit $\mathrm{RC}+\mathrm{S}^{\mathrm{TM}}$, currently in use under an investigational device exemption enables continuous intracranial EEG (iEEG) streaming during therapeutic EBS $[28,29]$. With continuous iEEG streaming and bidirectional connectivity the investigational Medtronic Summit $\mathrm{RC}+\mathrm{S}^{\mathrm{TM}}$ system provides a unique opportunity for long-term, ambulatory monitoring and quantitative evaluation of sleep during EBS therapy [28,29].

We collected ambulatory iEEG recordings from four patients with drug resistant epilepsy implanted with the investigational investigational Medtronic Summit $\mathrm{RC}+\mathrm{S}^{\mathrm{TM}}$ to track long term behavioral state dynamics. The patients received therapeutic DBS to the ANT bilaterally during concurrent, bilateral hippocampal (HPC) recording. We evaluated the feasibility and accuracy of automated behavioral state classification under different ANT stimulation frequencies $(2,7,100$ and $145 \mathrm{~Hz})[2,30$ 34] using three nights of data with available polysomnography (PSG) expert sleep annotations for each patient. A Naïve Bayes classifier $[35,36]$ was used for classifying iEEG signals into Wake, Rapid-Eye-Movement (REM), and non-REM (NREM: N2 \& N3). Subsequently, we deployed trained classifiers and analyzed continuous data from four patients totalling over 6 months of recorded iEEG data.

\section{Methods}

\subsection{Experimental Protocol}

This human subjects research study was carried out under an FDA IDE: G180224 and Mayo Clinic IRB: 18-005483 "Human Safety and Feasibility Study of Neurophysiologically Based Brain State Tracking and Modulation in Focal Epilepsy". The study is registered at https://clinicaltrials.gov/ct2/show/NCT03946618. The patients provided written consent in accordance with the IRB and FDA requirements [37]. Four subjects with drug resistant medial temporal lobe epilepsy (mTLE) (H1-4) were consented and implanted with the investigational Medtronic Summit $\mathrm{RC}+\mathrm{S}^{\mathrm{TM}}$ device $[29,37,38]$, with four 4-contact leads, targetting the hippocampus (HPC) and anterior nucleus of the thalamus (ANT) bilaterally. See supplementary data for additional surgical and clinical information.

We collected simultaneous polysomnography and HPC iEEG data in hospital and ambulatory settings. The simultaneous polysomnographic and iEEG recordings were collected over multiple days in the hospital setting to obtain gold standard sleep classifications based on expert review of scalp EEG (EKS) for subsequent traning, validation and testing of the iEEG-based automated classifier. Subsequently, continuous prospective automated classifications were made in naturalistic settings in ambulatory patients, without concurrent scalp recordings.

\subsubsection{Intracranial EEG Data Acquisition}

Intracranial EEG data were continuously collected using wireless streaming to a tablet computer as previously described by Kremen and Sladky et al. [37-39] with $250 \mathrm{~Hz}$ or $500 \mathrm{~Hz}$ sampling frequency. Data acquired at $500 \mathrm{~Hz}$ was down sampled to 
medRxiv preprint doi: https://doi.org/10.1101/2021.08.10.21261645; this version posted August 12, 2021. The copyright holder for this

preprint (which was not certified by peer review) is the author/funder, who has granted medRxiv a license to display the preprint in perpetuity.

All rights reserved. No reuse allowed without permission.

$250 \mathrm{~Hz}$. Impedance between the implanted device and electrode contacts was below $2 \mathrm{k} \Omega$ for all contacts during all experiments. We recorded long term iEEG data from four patients with the cumulative iEEG data spanning over 1,000 days, and here we analyzed at least 30 days for each of the subjects H1-4.

\subsubsection{Simultaneous Polysomnography and Intracranial EEG Streaming During Electrical Brain Stimulation}

Simultaneous HPC iEEG and polysomnography (scalp EEG, eye leads, chin leads) recording was conducted at different ANT EBS parameters $(2 \mathrm{~Hz}, 7 \mathrm{~Hz}, 100$ and $145 \mathrm{~Hz} ; 3-4 \mathrm{~mA} ; 90$ or $200 \mu$ s pulse width) over the course of three consecutive nights in the epilepsy monitoring unit (EMU). This provided standard reference state labels for training and testing of the behavioral state classifier. The Natus Medical Inc. Xltek electrophysiology system was used to acquire all PSG data with a common reference on the scalp and midline between the international $10-20 \mathrm{Cz}$ and Fz electrode positions. The scalp data were acquired at a sampling rate of $512 \mathrm{~Hz}$. The effect of ANT stimulation $(2 \mathrm{~Hz}, 7 \mathrm{~Hz}, 100$ and $145 \mathrm{~Hz})$ on HPC iEEG recordings, behavioral state classification based on HPC recordings, and sleep architecture was investigated. The details of the stimulation protocol are shown in Table S1 in the Supplementary Materials and illustrated in Figure 4. Three consecutive nights of continuous iEEG and PSG monitoring were used to train, validate, and test the automated classifiers (Figure 4).

\subsubsection{Sleep Scoring Using Scalp EEG}

For visual expert sleep stage scoring, all the PSG recordings were bandpass filtered between 0.3 and $75 \mathrm{~Hz}$ with a $60 \mathrm{~Hz}$ notch filter using six-order zero-phase Butterworth filters. We used electrodes that were placed in the standard 10-20 system locations. This included eye and chin electrodes for evaluation of eye movements and muscle activity for REM sleep scoring. Visual sleep scoring was done manually by an expert reviewer (EKS) in accordance with guidelines of American Association of Sleep Medicine [40] using a visualisation and analytical software tool CyberPSG (Certicon a.s.). Wakefulness was determined by the presence of eye blinks visualized in frontal scalp and eye leads, accompanied by posteriorly dominant alpha rhythm (8-12 Hz), comprising $>50 \%$ of the epoch. Slow-wave sleep (N2) was scored when low frequency delta activity was present accompanied by K-complexes or spindles. N3 was scored when high-voltage $(>75 \mu \mathrm{V})$, delta $(0.5-4 \mathrm{~Hz})$ activity on scalp EEG was present in at least $20 \%(6 \mathrm{sec})$ of the epoch in the frontal electrode derivations. A similar approach was used in previous studies [22,23,41]. In total, 12,182 sleep epochs were annotated by an expert reviewer using available PSG recordings for all patients. The distribution between individual sleep stages was Wake - $29.4 \%$, NREM1 - $4.8 \%$, NREM2 $37.7 \%$, NREM $3-15.7 \%$ and REM - $12.32 \%$. The block diagrams for experiment setup and data pipelines are shown in Figure 1.

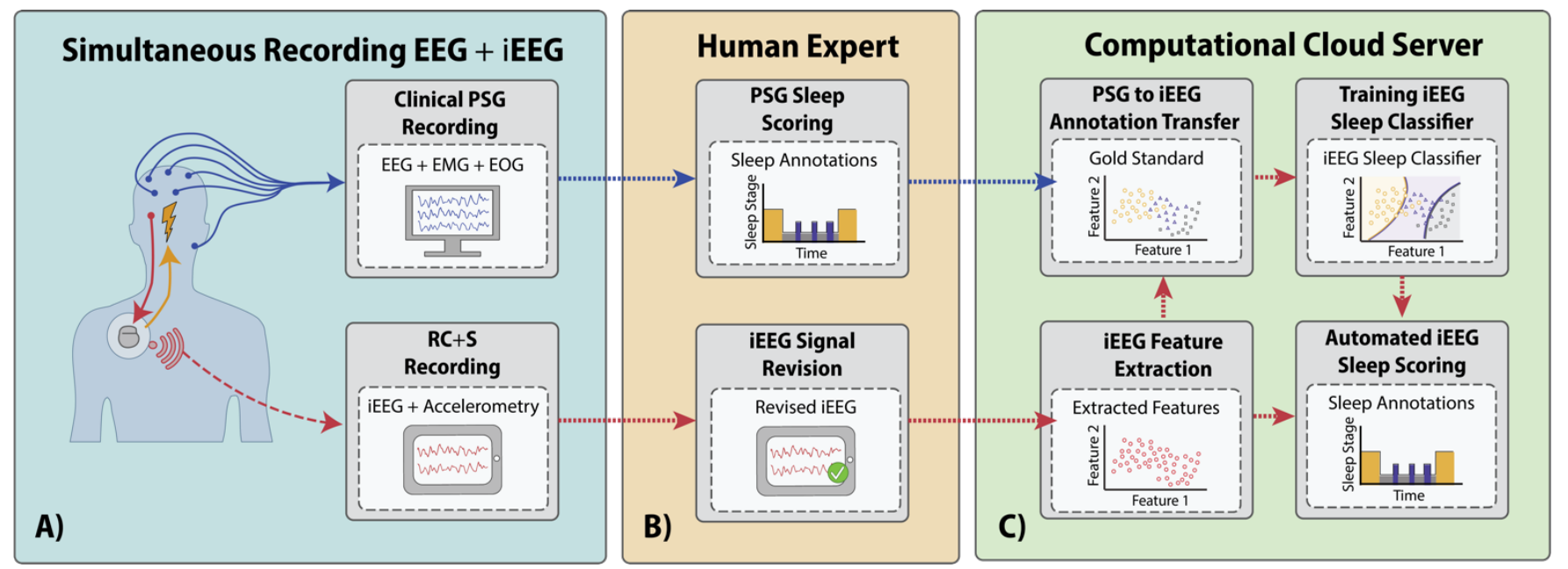

Figure 1. Block-diagram of the process for training, validation, and testing of an automated sleep classifier using simultaneous polysomnography and intracranial EEG (iEEG) neural recordings. A) Schematic of the simultaneous scalp and intracranial iEEG recordings B) The expert gold standard sleep scoring from polysomnography is used to create labeled data to develop the automated sleep classifier [37]. C) Direct comparison of the expert sleep scores that are used to evaluate performance of the iEEG based classifier. 
medRxiv preprint doi: https://doi.org/10.1101/2021.08.10.21261645; this version posted August 12, 2021. The copyright holder for this preprint (which was not certified by peer review) is the author/funder, who has granted medRxiv a license to display the preprint in perpetuity.

All rights reserved. No reuse allowed without permission.

\subsubsection{Selection of an Intracranial Electrode for Sleep Scoring}

The investigational Medtronic Summit $\mathrm{RC}+\mathrm{S}^{\mathrm{TM}}$ enables data streaming from a total of 4 bipolar sensing channels at a time that can be selected from the 16 electrodes. The fact that some electrode contacts are placed in the epileptic focus, a region with a propensity to show pathological activity such as interictal epileptiform discharges (IEDs), led us to investigate models for behavioral state classification using a single electrode contact. Our approach uses a single selectable sensing channel that is optimal for sleep scoring. Individual channels were evaluated for each subject based on the following factors: rate of IEDs, rate of subclinical seizures, and magnitude of EBS artifacts. We picked the electrode with the fewest of all the above. To illustrate the variable IED-rate within a single subject, patient H1 exhibited 500-5,200 IEDs per hour across different recording channels (Figure 3) and behavioral states [37]. EBS-induced artifacts are important factor to consider during electrode selection. The impact of ANT stimulation on HPC iEEG signal spectrum for cases of 2 and $7 \mathrm{~Hz}$ low frequency stimulation shows that the power spectrum is disrupted with peaks in bands of stimulation frequency and its harmonics (Figure 2).

\section{H3}

A)

No Stimulation

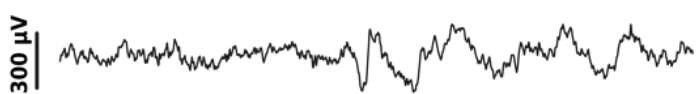

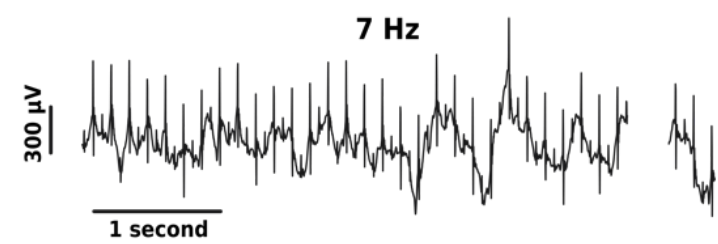

B)
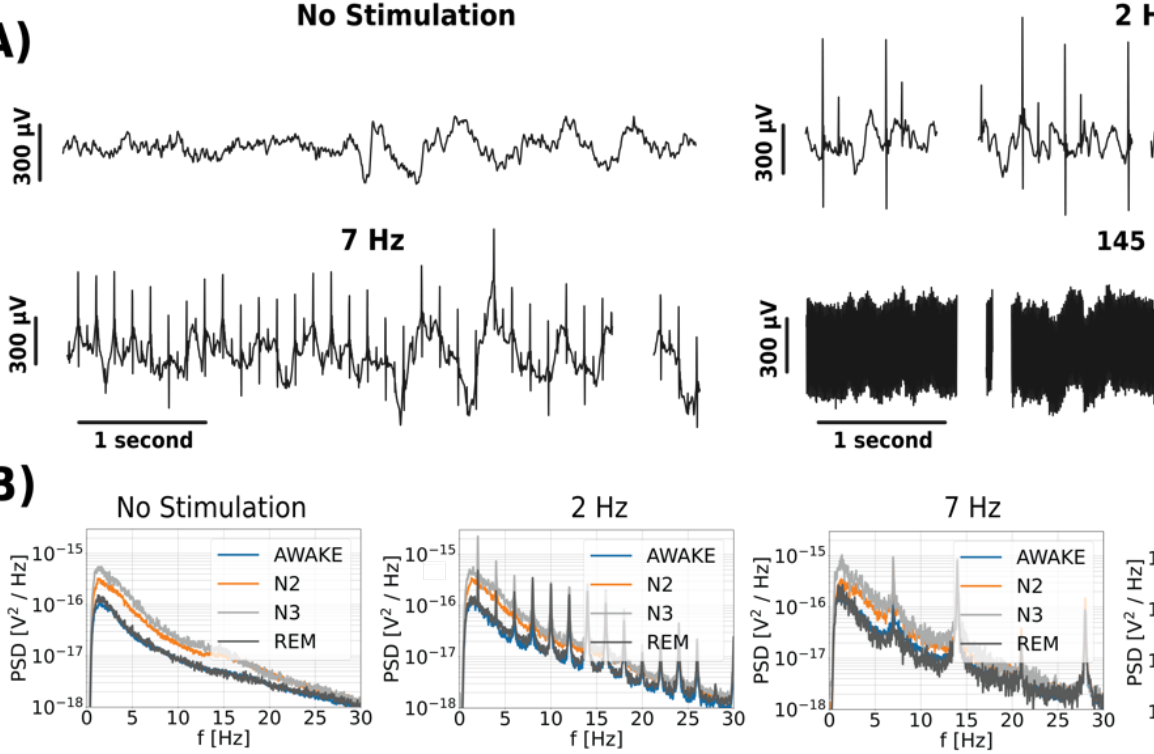

$2 \mathrm{~Hz}$

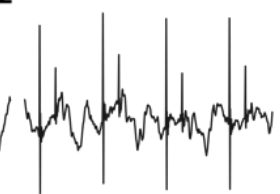

$145 \mathrm{~Hz}$
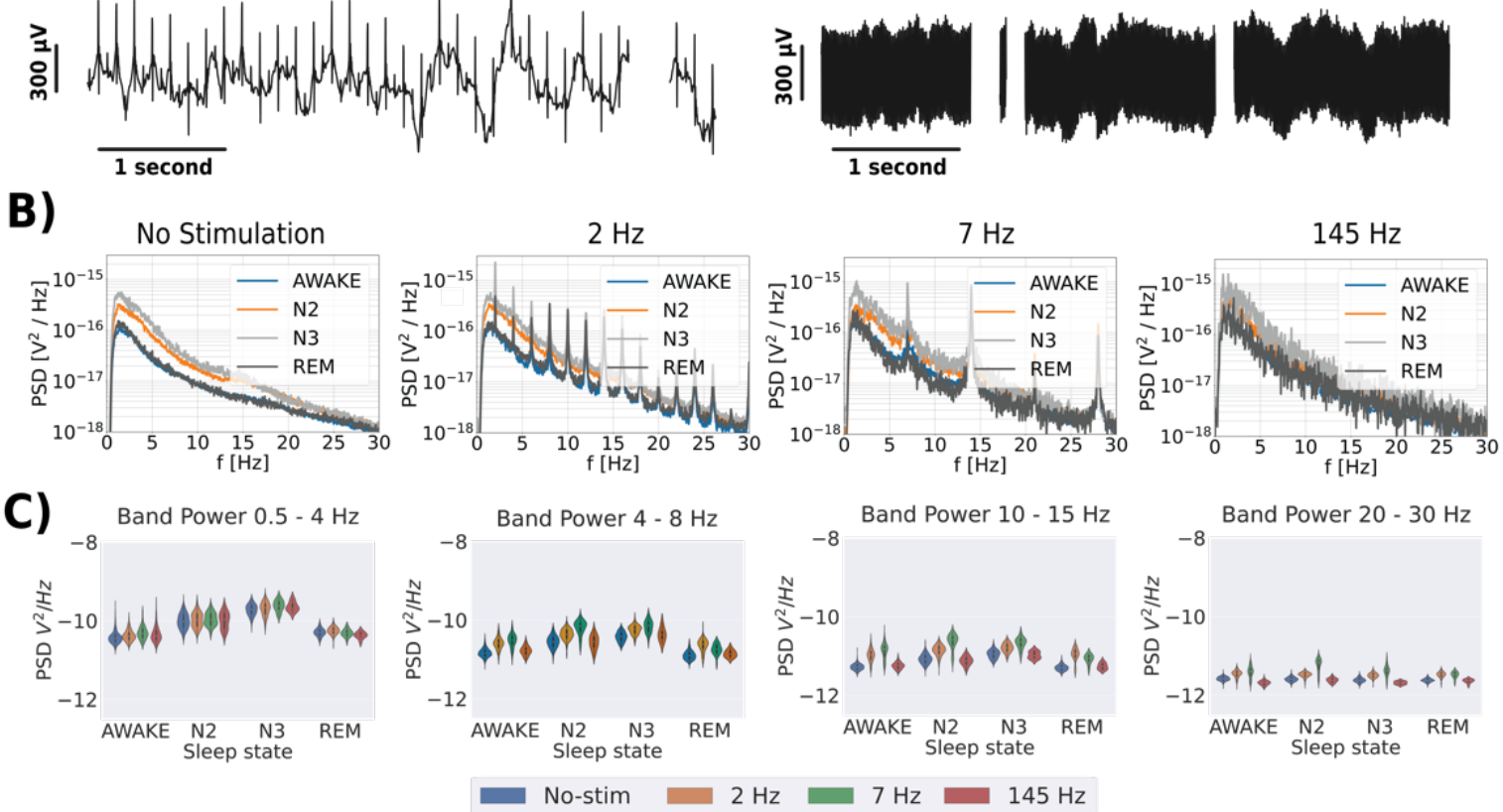

Figure 2. The effect of ANT EBS on iEEG signals. A) The iEEG recorded from right hippocampus (HPC) (patient H3) for different ANT EBS frequencies (No EBS, 2, 7 and $145 \mathrm{~Hz}$ ). The ANT stimulation artifact is clearly apparent on the HPC iEEG timeseries and at $145 \mathrm{~Hz}$ obscures the iEEG signal B) Frequency domain represented by power spectral density (PSD) for different ANT EBS frequencies (No EBS, 2, 7 and $145 \mathrm{~Hz}$ ): average of each sleep phase spectrum across three nights, estimated by Welch's method (Awake, N2, N3, REM); C) Power in band features (0.5- $4 \mathrm{~Hz} ; 4-8 \mathrm{~Hz} ; 10-15 \mathrm{~Hz} ; 20-30 \mathrm{~Hz}$ ) extracted from raw HPC iEEG signals from each sleep states (Awake, N2, N3, REM), over three nights. These data from subject H3 are representative of all patients. 
medRxiv preprint doi: https://doi.org/10.1101/2021.08.10.21261645; this version posted August 12, 2021. The copyright holder for this preprint (which was not certified by peer review) is the author/funder, who has granted medRxiv a license to display the preprint in perpetuity.

All rights reserved. No reuse allowed without permission.

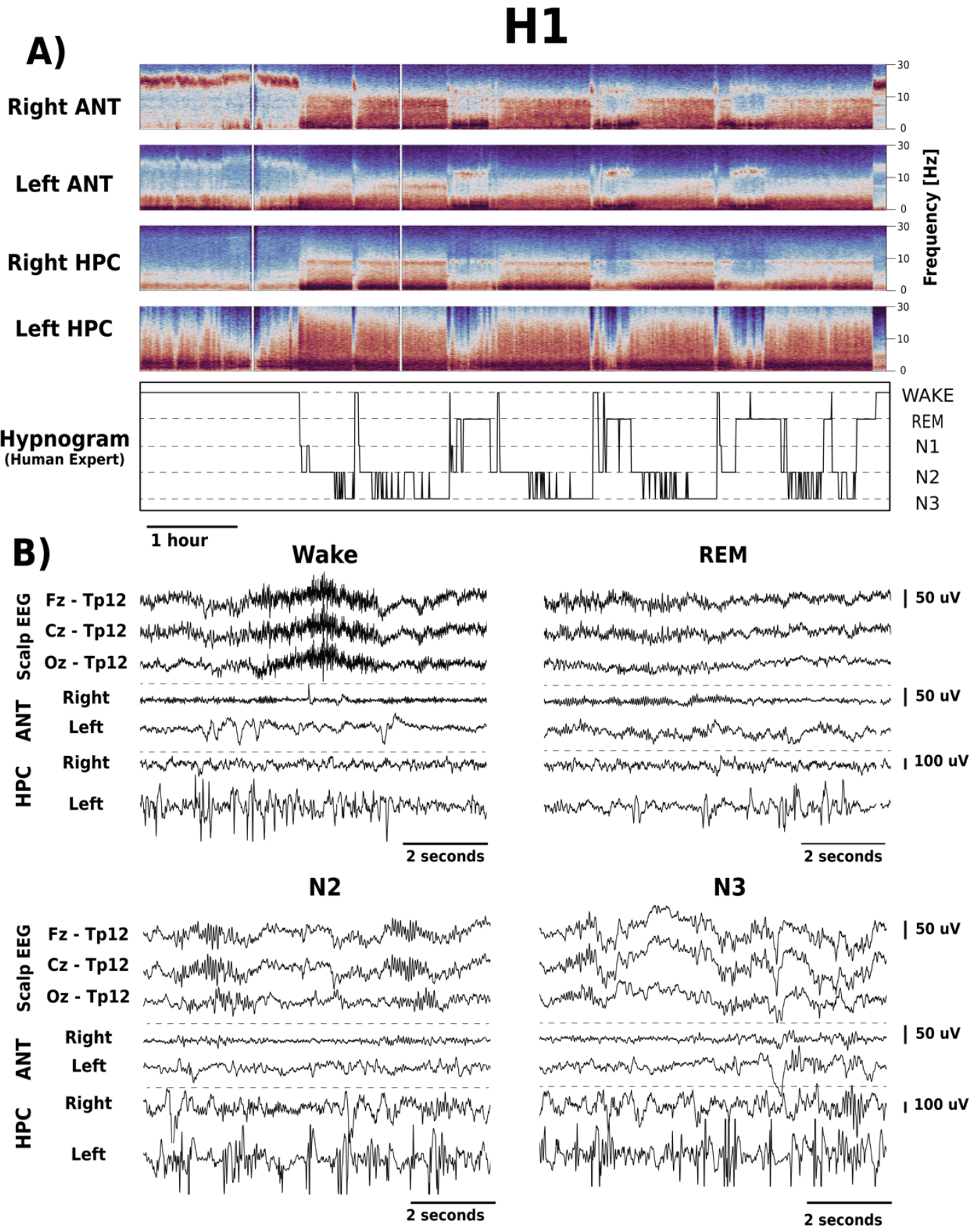

Figure 3. Intracranial EEG (iEEG) signal changes between different behavioral states (Wake, REM, NREM 2 and NREM 3). A) Spectrograms of iEEG signals recorded from right and left anterior nucleus of thalamus (ANT) and hippocampus (HPC), show Wake, REM, and NREM changes. There are differences between iEEG signals recorded from right and left ANT and HPC related to the electrophysiological signatures of epilepsy e.g., interictal epileptiform discharges are increased on the left (patient H1). B) Simultaneous scalp-EEG (Fz, CZ and Oz referenced to TP12) and iEEG (bipolar Left ANT, Right ANT, Left HPC, Right HPC) recordings for wake, REM, NREM 2 and NREM 3. 
medRxiv preprint doi: https://doi.org/10.1101/2021.08.10.21261645; this version posted August $12,2021$. The copyright holder for this

preprint (which was not certified by peer review) is the author/funder, who has granted medRxiv a license to display the preprint in perpetuity.

All rights reserved. No reuse allowed without permission.

\subsection{Automated Sleep Classification}

We implemented a classification model utilizing a Naïve Bayes Classifier [35,36,42] with relative power in band (PIB) features extracted from a single iEEG channel to classify 30 second long epochs into the standard sleep categories Awake, N2, N3, REM. The sleep state N1 was excluded due to the insufficient number of samples among the available gold standard data (Table 1).

\subsubsection{Data Processing}

The iEEG and PSG recordings were stored in the Multi-Scale Electrophysiology Format (MEF) [43] and imported into Python using a Python library "pymef" available on GitHub https://github.com/msel-source/pymef. The sleep scoring gold standard annotations were exported from the CyberPSG software and imported into Python using software package "Automated iEEG Sleep Scoring” (AISC)

iEEG signals used for automated sleep scoring were filtered using 3rd order IIR Butterworth zero-phase filter at $40 \mathrm{~Hz}$, and those acquired at $500 \mathrm{~Hz}$ were down sampled to $250 \mathrm{~Hz}$. Subsequently, the iEEG signals were segmented into 30-second-long epochs corresponding to the gold standard annotations. All epochs with more than $15 \%$ of samples missing due to packet drops in the wireless data iEEG streaming were excluded, leaving a total of 11,091 epochs from all subjects. The segments were distributed across all sleep stages (Wake - $35 \%$; NREM 1 - 5\%; NREM 2 - 34\%; NREM $3-15 \%$; REM - $11 \%$ ), and across different stimulation frequencies (no-EBS - 52\%; $2 \mathrm{~Hz}$ EBS - $34 \%$; $7 \mathrm{~Hz}$ EBS - $7 \%$; high-frequency - 100 or $145 \mathrm{~Hz}$ EBS $22 \%$ ). Additional details are provided in Table S2 in the Supplementary Materials.

Missing samples within short packet drops were replaced by the average value of the corresponding 30 -second epoch. The data were then filtered by a $0.5-40 \mathrm{~Hz}$ band-pass filter and power spectral density (PSD) was estimated using Welch's method for each 30 -second-long epoch using a 10 -second window with 5 second overlap.

We extracted two sets of PIB features from the following bands: $0.5-5 \mathrm{~Hz}, 4-9 \mathrm{~Hz}, 8-14 \mathrm{~Hz}, 11-16 \mathrm{~Hz}, 14-20 \mathrm{~Hz}$ (low beta) and $20-30 \mathrm{~Hz}$ (high beta). Frequency bands were selected based on prior automated sleep classification work using intracranial and scalp EEG $[22-25,37,38,40]$ and preliminary analysis of patient $\mathrm{H} 1$. The first set of features was power in band relative to the power of the whole spectrum from $0.5-30 \mathrm{~Hz}$. The second set of features consisted of the relative power in band calculated as a ratio of frequency bands. The power in band ratio was estimated for all non-repeating two-sample ascending combinations within the set of all frequency bands, i.e. delta vs theta, delta vs alpha, etc. Subsequently, a decadic logarithm transformation was applied to all features introduced above.

\subsubsection{Cancelling of Band Power at Stimulation Frequencies}

EBS-induced artifacts alter the PIB features as evident in Figure 2. To reduce the impact of EBS-induced artifacts on extracted features, and thus on classification performance, we applied PIB cancelling - setting the power in band to zero. This way, we attenuated frequency bands impacted by the EBS-induced stimulation artifacts $-2 \& 7 \mathrm{~Hz}$ and higher harmonic frequencies. Based on a preliminary data inspection, we eliminated the frequency band $1.5-2.5 \mathrm{~Hz}$ for $2 \mathrm{~Hz}$ stimulation, and the $6-8 \mathrm{~Hz}$ band for the $7 \mathrm{~Hz}$ stimulation and corresponding higher harmonic frequencies eliminating all by EBS impacted frequency bands. PIB cancelling was performed separately for each stimulation paradigm.

\subsubsection{Modes of Operation: Chronic Automated Classification under Different Stimulation Settings}

We trained a patient-specific classifier using hippocampal iEEG data during stimulation-free periods then tested and validated the classification performance using data recorded under different ANT stimulation programs $(2,7,100$ \& $145 \mathrm{~Hz})$. There are practical limitations to exposing patients to multiple nights of monitoring in the EMU to screen possible stimulation programs and evaluate the impact of thalamic stimulation on the precision and stability of the automated sleep classifier. We tested the feasibility of transferring classification models, so called transfer learning (TL) [44], between no EBS and multiple EBS frequencies $(2 \mathrm{~Hz}, 7 \mathrm{~Hz}, 100 \mathrm{~Hz}, 145 \mathrm{~Hz}$ ) EBS separately (Figure 4). Therefore, we validated the classifiers in real-life scenario when only a single night of concurrent PSG and iEEG is available as described in section B3 "Sleep Scoring with scalp EEG". We also investigated the impact of PIB cancelling on classification performance by training and validating classifiers for all subjects under different PIB cancelling protocols: no PIB cancelling and EBS frequency specific PIB cancelling (Table S2 Supplementary Materials, Figure 4). 
A) Day $1 \square$ Day $2 \triangle$ Day 3 的
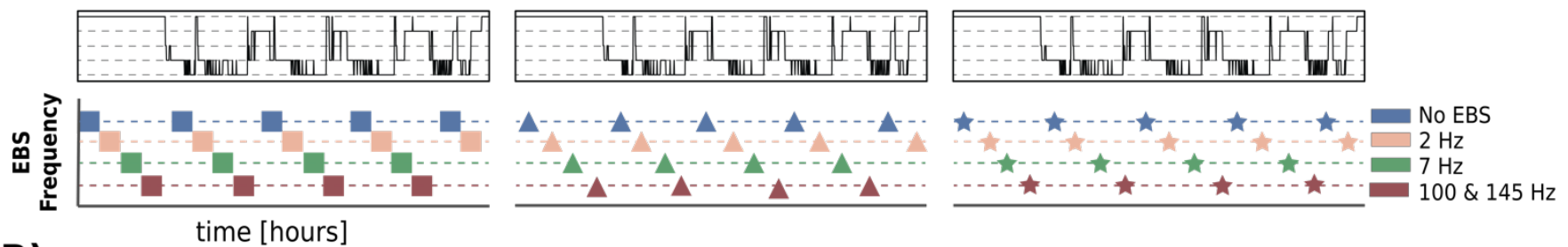

B)
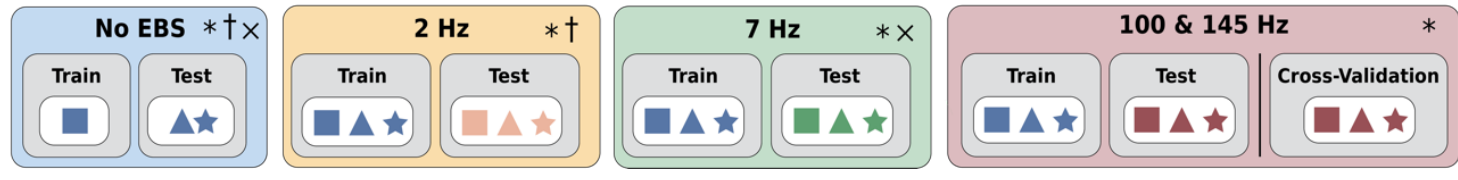

Figure 4. A scheme of iEEG data utilization throughout the training and testing of classifiers under multiple ANT stimulation programs. A) Illustration of iEEG data sampling under different ANT stimulation programs. B) A scheme of collected iEEG data utilization for training and testing of automated sleep classification under different ANT stimulation programs (No EBS, 2 Hz, $7 \mathrm{~Hz}, 100$ \& $145 \mathrm{~Hz}$ ). Each experiment was performed * - without applying the method of PIB cancelling; $\boldsymbol{\dagger}$ - with PIB cancelling specific to $2 \mathrm{~Hz}$ stimulation; $\times$ - with PIB cancelling specific to $7 \mathrm{~Hz}$ stimulation under each stimulation paradigm. Details are listed in Table S1 and Table S2 in Supplementary Materials.

\section{a) No EBS}

In the first experiment, we used iEEG data collected from three consecutive days of HPC recording (H1-H4) in the absence of ANT EBS to classify Wake, REM, N2, and N3 sleep stages. Available expert sleep scoring annotations were available for all patients. We used only the first night of available iEEG data without EBS to train a patient-specific automated sleep classifier for each subject (H1-H4). Subsequently, trained classifiers were pseudo-prospectively tested using the second and third night.

\section{b) Low Frequency EBS}

We investigated the feasibility of deploying the classifiers trained using no EBS data to the iEEG data recorded under low frequency $(2 \& 7 \mathrm{~Hz})$ ANT EBS and contaminated by EBS-induced artifacts. The experiment was performed with and without the stimulation active PIB cancelling and for all subjects.

\section{c) High Frequency EBS}

Like the previous experiment, we tested the feasibility of reusing the stimulation-free classifier for the iEEG data recorded while delivering high frequency thalamic stimulation.

Additionally, we performed a leave-out cross-validation (CV) testing for high-frequency EBS data in each patient since we hypothesize that high-frequency EBS may decrease signal-to-noise ratio (SNR), and also modulate and alter HPC iEEG beyond simple stimulation artifacts. The CV testing was performed in 100 iterations, with $80 \%$ of all iEEG data recorded under a high frequency EBS setup used for the automated sleep classifier training for each patient. The rest of the data was used for testing. The data were sampled proportionally in all classification categories.

\subsubsection{Post-Processing: Hypnogram Correction Rules for Automated Long-Term Data with Dropouts}

In this study the encrypted iEEG data are wirelessly transmitted between different hardware devices (implanted neural stimulator, tablet, and cloud) before encryption and storage on the tablet hard drive [38]. Wireless data transmission in the home environment can suffer from data loss in the form of dropped packets due to poor wireless signal connections between individual devices. Both short ( $<5$ minutes) and long ( $>5$ minutes $)$ data drops were present in our recordings. Short data drops account for up to 2.9 hours of missing data in total every day (patients H1-H4). To address the issue of missing data during different sleep state transitions or sleep states we employed a heuristic to assign short data drops to specific classes:

1) If a short data drop ( $<5$ minutes) is preceded by at least 5 minutes of a classified sleep stage that consistently yield the same sleep stage, the data drop is assigned the sleep stage of the preceding prediction. 
medRxiv preprint doi: https://doi.org/10.1101/2021.08.10.21261645; this version posted August 12, 2021. The copyright holder for this

preprint (which was not certified by peer review) is the author/funder, who has granted medRxiv a license to display the preprint in perpetuity.

All rights reserved. No reuse allowed without permission.

2a) If a short data drop ( $<5$ minutes) is preceded by at least 5 minutes of "Awake" state predictions and followed by a REM stage prediction, the data drop is assigned to "Awake".

2b) Any epoch that is classified as "REM" sleep that follows at least 5 minutes of "Awake" is assigned to "Awake".

3) If a sequence of predicted sleep states with a duration of at least 5 minutes consists of any combination of "N2" and "N3" and is followed by a data drop with a maximum duration of 5 mins, and the following predicted sleep state is either "N2" or "N3", the void is assigned to a generic non-REM sleep category "N".

4) If a sequence of predicted sleep states with a duration of at least 5 minutes consists of any combination of "N2", "N3" and "REM" and is followed by a data drop with a maximum duration of 5 mins, and the following predicted sleep state is either "N2", "N3" or "REM", the void is assigned to a generic sleep category SLEEP.

\subsection{Ambulatory Behavioral State Classification Environment}

The trained models for automated iEEG behavioral state classification were deployed onto a handheld epilepsy personal assist device (EPAD) and in a cloud system for automated behavioral state classification. Over 190 days in total was analysed in four people with epilepsy (H1-4).

\subsection{Statistics}

Remaining cognizant of the unbalanced datasets in this study, we calculated the F1-score classification metric for binary classification of each category and weighted the F1-score average for multi-class classification. The F1-score was calculated as follows

$$
F 1=2 \cdot \frac{\text { precision } \cdot \text { recall }}{\text { precision }+ \text { recall }}
$$

Precision, or positive predictive value $=\frac{\mathrm{TP}}{\mathrm{TP}+\mathrm{FP}}$ and recall, or sensitivity $=\frac{\mathrm{TP}}{\mathrm{TP}+\mathrm{FN}}$ are defined in terms of true positive $(\mathrm{TP})$, false positive (FP) and false negative (FN) classification.

\subsection{Reproducible Research - Code Sharing}

The Bioelectronics Neurophysiology and Engineering Lab is committed to sharing data and code to facilitate reproducible research. All codes are publicly available on Github in a Python software package called Automated iEEG Sleep Classifier (AISC) available on https://github.com/mselair/AISC. The data are available upon request.

\section{Results and Discussion}

We developed and tested an approach for fully automated behavioral state classification using a single bipolar electrode iEEG data recorded from HPC in patients with epilepsy implanted with the investigational Medtronic Summit $\mathrm{RC}+\mathrm{S}^{\mathrm{TM}}$ system. We recorded continuous iEEG data in the hospital epilepsy monitoring unit for three consecutive days and nights in four patients. We trained, validated, and tested the automated behavioral state classification using visually scored, gold standard polysomnography. We investigated and verified that the classifier can be trained on one night of the data and deployed under various ANT EBS paradigms (high and low frequency stimulation) with high accuracy classification scores. We then deployed the classifiers in a distributed fashion onto a patient handheld tablet device to track longitudinal sleep patterns in four PWE living in their natural environment.

\subsection{Automated Sleep Scoring Using iEEG Recordings without Concurrent Electrical Brain Stimulation}

In the absence of ANT stimulation, the overall classification performance was 0.858 (Table 1) and the results suggest that classifying Awake/NREM/REM states from a single hippocampal sensing channel has good precision and sensitivity for each behavioral state, with the worst performance for REM sleep with an average F1-score of 0.667. While classification of combined N2 \& N3 as NREM slow wave sleep is very reliable with F1-score 0.94, classifier performance for N2 and N3 individually, is modest HPC (F1_N2 $\left.=0.600, \mathrm{~F} 1 \_\mathrm{N} 3=0.635\right)$. The graphoelements that distinguish N2 sleep may be difficult 
medRxiv preprint doi: https://doi.org/10.1101/2021.08.10.21261645; this version posted August 12, 2021. The copyright holder for this preprint (which was not certified by peer review) is the author/funder, who has granted medRxiv a license to display the preprint in perpetuity.

All rights reserved. No reuse allowed without permission.

Journal XX (XXXX) XXXXXX

Author et al

to capture in our classification approach which relies on 30 second power in band features. Detailed results for all subjects are shown in Table 1.

To the best of our knowledge, this is the first study to pseudo-prospectively test automated iEEG sleep scoring using single channel iEEG data on multi-day data using gold standard annotations. Previous studies utilized semi-gold standard annotations [22], or performed only leave-out cross validation testing [24]. Therefore, we performed a proof-of-concept evaluation of an automated long-term sleep classification for data recorded using INSS in patients with epilepsy.

\subsection{Assessment of Automated Sleep Scoring from Hippocampal iEEG During Low Frequency and High Frequency Electrical Brain Stimulation}

We trained and tested a behavioral state classification model for multiple EBS frequencies $(2 \mathrm{~Hz}, 7 \mathrm{~Hz}, 100$ \& $145 \mathrm{~Hz})$ using single bipolar channel iEEG data with available gold standard annotations acquired during three consecutive nights for the subjects (H1-4).

Table 1. Results of automated behavioral sleep state classification (F1-score) into Awake, REM, N2, N3 sleep categories for all subjects under various settings of electrical brain stimulation (EBS) in anterior nucleus of thalamus (ANT). Values marked by * were achieved using fewer than 10 samples and therefore are not considered valid, however, stated for consistency.

\begin{tabular}{|c|c|c|c|c|c|c|c|}
\hline $\begin{array}{c}\text { EBS } \\
\text { Frequency }\end{array}$ & Subject & Awake & REM & N2 & N3 & NREM & All \\
\hline \multirow{5}{*}{ No EBS } & H1 & .958 & .795 & .450 & .726 & .929 & .926 \\
\hline & H2 & .848 & .660 & .740 & .338 & .944 & .893 \\
\hline & H3 & .716 & .448 & .588 & .714 & .816 & .722 \\
\hline & $\mathrm{H} 4$ & .798 & .763 & .621 & .763 & .924 & .890 \\
\hline & Average & .830 & .667 & .600 & .635 & .903 & .858 \\
\hline \multirow{5}{*}{$2 \mathrm{~Hz}$} & H1 & .991 & .848 & .364 & .721 & .932 & .931 \\
\hline & $\mathrm{H} 2$ & .960 & .714 & .552 & .440 & .960 & .940 \\
\hline & H3 & .735 & .484 & .799 & .717 & .932 & .826 \\
\hline & $\mathrm{H} 4$ & .696 & .491 & .169 & .522 & .788 & .781 \\
\hline & Average & .846 & .634 & .471 & .600 & .903 & .870 \\
\hline \multirow{5}{*}{$7 \mathrm{~Hz}$} & $\mathrm{H} 1$ & .974 & $.353^{*}$ & .444 & .690 & .949 & .941 \\
\hline & $\mathrm{H} 2$ & .976 & .914 & .396 & .491 & .978 & .973 \\
\hline & H3 & .870 & .903 & .886 & .810 & .935 & .918 \\
\hline & H4 & - & - & - & - & - & - \\
\hline & Average & .923 & .789 & .557 & .609 & .936 & .919 \\
\hline \multirow{5}{*}{$\begin{array}{c}\text { High } \\
\text { Frequency } \\
(100 \& 145 \mathrm{~Hz})\end{array}$} & H1 & .970 & .894 & .564 & .771 & .987 & .975 \\
\hline & $\mathrm{H} 2$ & .703 & .772 & .613 & .176 & .944 & .902 \\
\hline & H3 & .899 & $.716^{*}$ & .693 & $.000^{*}$ & .857 & .899 \\
\hline & $\mathrm{H} 4$ & .774 & .800 & .841 & .673 & .971 & .939 \\
\hline & Average & .837 & .822 & .678 & .540 & .940 & .929 \\
\hline
\end{tabular}

ANT stimulation can influence hippocampal background activity and elicit evoked responses in the hippocampus. Despite the potential impact of ANT stimulation on HPC-based sleep classification, we observed acceptable classifier performance during both high and low frequency ANT stimulation. Although $2 \mathrm{~Hz}$ EBS, corrupted the iEEG power spectrum at the stimulation frequency and its harmonics $(2,4,6, \mathrm{~Hz}$, etc), the average performance across all subjects was good (F1_ALL $=$ 0.870). Awake ( F1_Awake $=0.846)$ and NREM $\left(F 1 \_N R E M=0.903\right)$ classification precision was superior to REM (F1_REM $=0.634)$. Classifier performance was slightly better during $7 \mathrm{~Hz}$ stimulation $\left(\mathrm{F} 1 \_\mathrm{ALL}=0.919\right)$ for Awake $\left(\mathrm{F} 1 \_A w a k e=0.923\right)$, and NREM (F1_NREM = 0.936) states, and notably stronger for REM $\left(\mathrm{F} 1 \_\right.$REM $\left.=0.789\right)$. The results also highlight the challenge of differentiating Awake from REM using a single channel of HPC iEEG (Figure 5). 
medRxiv preprint doi: https://doi.org/10.1101/2021.08.10.21261645; this version posted August 12, 2021. The copyright holder for this

preprint (which was not certified by peer review) is the author/funder, who has granted medRxiv a license to display the preprint in perpetuity.

All rights reserved. No reuse allowed without permission.

Given the clinical use of high frequency ANT EBS to treat epilepsy [33], it was important to evaluate the feasibility of reusing a classifier trained on HPC iEEG data without concurrent stimulation to HPC iEEG data acquired during high frequency ANT stimulation. We evaluated high ANT stimulation frequencies $(100 \& 145 \mathrm{~Hz})$. The automated classifier was able to differentiate Awake, NREM, and REM (F1_Awake $=0.837, \mathrm{~F} 1 \_$NREM $=940, \mathrm{~F} 1 \_$REM $=0.822$, and F1_ALL $\left.=0.929\right)$ behavioral states with good classification score. The differentiation of $\mathrm{N} 2$ from N3, using power in band features as we did here, was modest.

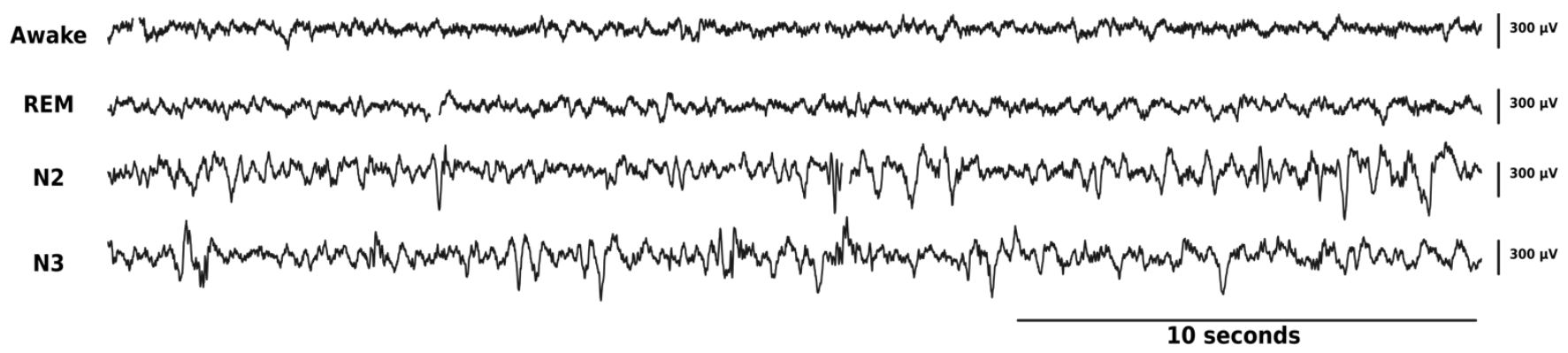

Figure 5. Samples of 30-second epochs of raw data recorded in right HPC channel during multiple behavioral states (gold standard classification): from top to bottom: Awake, REM, NREM 2 and NREM3.

\subsection{Ambulatory Behavioral State Classification in Natural Environment}

After building the patient-specific models using 3 days of inpatient recordings, we then prospectively deployed the behavioral state classifiers on continuous, long-term HPC iEEG data totalling over 190 days in four human subjects (H1-H4). The algorithms for automated iEEG behavioral state classification were deployed onto a handheld epilepsy personal assist device (EPAD) and in a cloud system. The presentation layer, a web browser interface for long-term iEEG-data (eHealth Dashboard) (Figure 6) monitoring from patients implanted with investigational Medtronic Summit $R C+S^{\mathrm{TM}}$ integrated with local (EPAD) and distributed (Cloud) computing resources was utilized to present automated sleep staging together with patient seizure and medication logs for physician review (Figure 6). On average, subjects got $7.91 \pm 1.96$ hours of sleep a day with $5.76 \pm 1.23$ hours spent in NREM and 2.05 \pm 1.18 hours in REM sleep. Evaluation of the influence of different stimulation paradigms and seizures on sleep architecture remain an interest for future research. The presentation layer providing integration of multiple levels of information (seizure rates, interictal epileptiform discharges, sleep) is essential for this research out.

\section{Conclusions}

Sleep disruption is a common comorbidity of epilepsy and important for optimization of EBS. Reliable automated behavioral state classification in ambulatory subjects during ANT-EBS is needed to optimize EBS therapy. Here we describe an approach for reliable automated behavioral state classification using data from a single HPC electrode in the setting of concurrent ANT EBS. The performance of patient specific behavioral state classification models trained, validated, and tested on concurrently recorded scalp polysomnography and HPC iEEG show good classification of wake and NREM (N2+N3) sleep with and without ANT EBS $(2 \mathrm{~Hz}, 7 \mathrm{~Hz}, 100 \mathrm{~Hz}$ and $145 \mathrm{~Hz})$. Automated classification of behavioral states (wake, NREM \& REM sleep) was deployed on a handheld and cloud platform and used to further characterize long-term sleep profiles in ambulatory human subjects living in their natural environment. The results highlight, however the relative challenge of differentiating wake from REM and differentiating NREM2 from NREM3 using only a single channel of HPC iEEG. The challenge for distinguishing NREM2 from NREM3 likely reflects the bipolar local field potential recording in hippocampus from relatively closely spaced electrodes is less well suited for measuring widespread delta activity seen on the scalp and used for visual sleep scoring.

This work advances efforts to better understand the bidirectional relationship between sleep, epilepsy, and the impact of EBS. The ability to classify behavioral state with a compact algorithm embedded in INSS devices, or on local and distributed computing resources [21], enables novel closed-loop stimulation protocols that can adaptively respond to changing brain dynamics. Near term applications include circadian EBS paradigms where stimulation during sleep and wake are selected to optimize sleep, epilepsy, and comorbidities. The data are mixed as to whether high frequency stimulation used in SANTE for 
medRxiv preprint doi: https://doi.org/10.1101/2021.08.10.21261645; this version posted August 12, 2021. The copyright holder for this preprint (which was not certified by peer review) is the author/funder, who has granted medRxiv a license to display the preprint in perpetuity.

All rights reserved. No reuse allowed without permission.

reducing seizures may negatively impact sleep, mood, and memory $[3,19,45]$. For patients who commonly have diurnal seizure patterns, such as temporal lobe epilepsy where seizures occur primarily in late morning and early afternoon [13-15], may benefit from different EBS during the night when the physiological benefits of sleep are critical to normal brain health. Lastly, the selective application of EBS in post-ictal slow wave sleep may prove useful for disrupting pathological seizure related consolidation $[41,46]$.

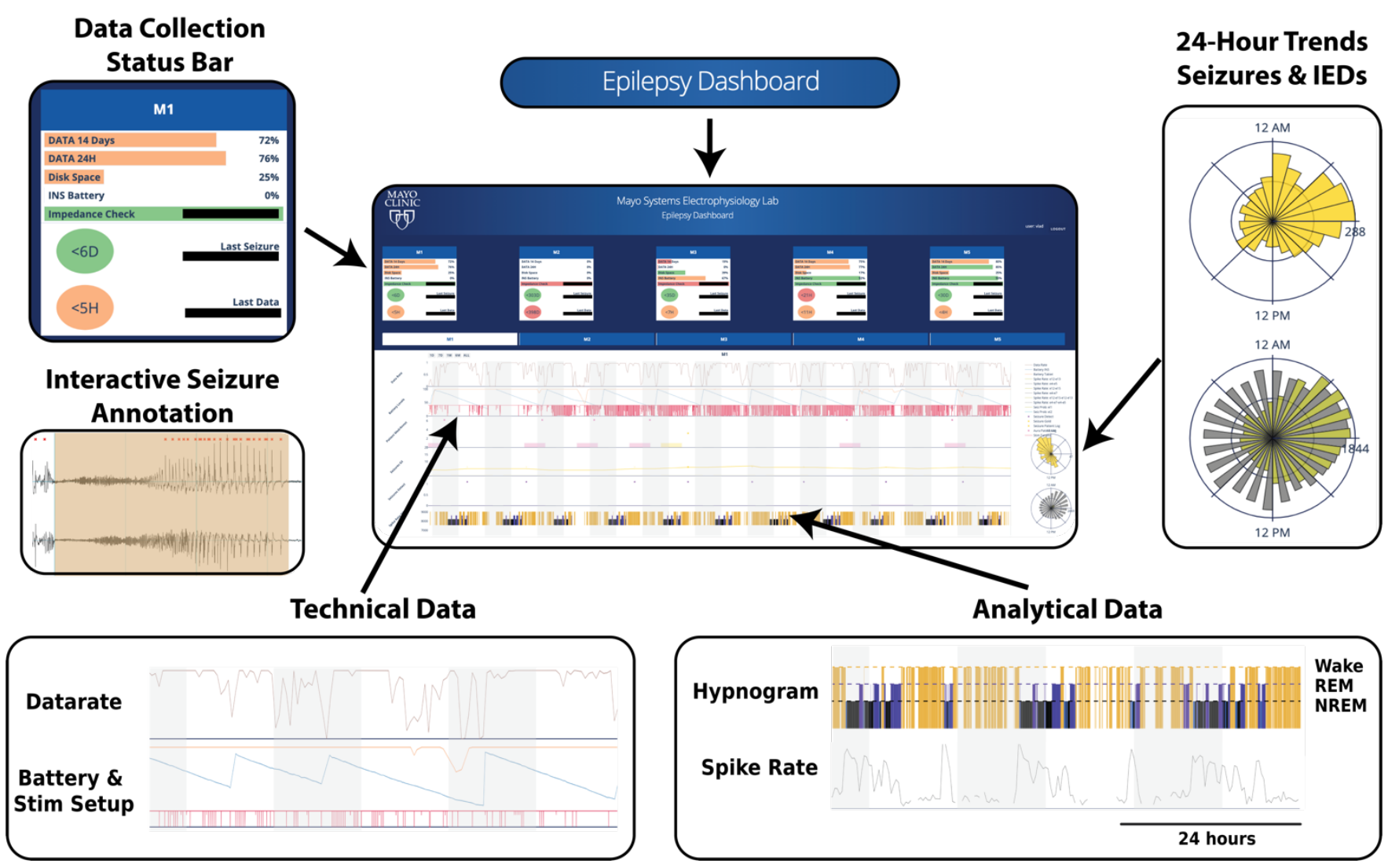

Figure 6. Web-based Epilepsy Dashboard: Trained algorithms deployed on a patient handheld tablet and a cloud system with a web browser user interface for physician to review technical data, patient annotations, gold-standard seizure annotations, and monitoring of long-term iEEG-data, epilepsy biomarkers (such as interictal epileptiform discharge activity), and automated sleep scoring.

\section{Acknowledgements}

Funding: This work was supported by NIH Brain Initiative UH2\&3 NS095495 Neurophysiologically-Based Brain State Tracking \& Modulation in Focal Epilepsy, DARPA HR0011-20-2-0028 Manipulating and Optimizing Brain Rhythms for Enhancement of Sleep (Morpheus), Mayo Clinic, and Medtronic Inc. Medtronic provided the investigational Medtronic Summit $\mathrm{RC}+\mathrm{S}^{\mathrm{TM}}$ devices. V.K. was partially supported by institutional funding of Czech Technical University in Prague, Czech Republic.

\section{Disclosures}

GW, BB, JVG, and BL are named inventor for intellectual property developed at Mayo Clinic and licensed to Cadence Neuroscience Inc. BNL royalties are waived to his Mayo Clinic research account. GW has licensed intellectual property developed at Mayo Clinic to NeuroOne, Inc. BL, GW, and NG in an investigator for the Medtronic Deep Brain Stimulation Therapy for Epilepsy Post-Approval Study (EPAS). VK consults for Certicon a.s. IB has received compensation from an 
medRxiv preprint doi: https://doi.org/10.1101/2021.08.10.21261645; this version posted August 12, 2021. The copyright holder for this

preprint (which was not certified by peer review) is the author/funder, who has granted medRxiv a license to display the preprint in perpetuity.

All rights reserved. No reuse allowed without permission.

internship with Cadence Neuroscience Inc., for work unrelated to the current publication. Mayo Clinic has received research support and consulting fees on behalf of GW, BNL and BB from UNEEG, NeuroOne Inc., Epiminder, Medtronic Plc., and Philips Neuro.

\section{References}

[1] Morrell M J 2011 Responsive cortical stimulation for the treatment of medically intractable partial epilepsy Neurology 77 1295304

[2] Nair D R, Laxer K D, Weber P B, Murro A M, Park Y D, Barkley G L, Smith B J, Gwinn R P, Doherty M J, Noe K H, Zimmerman R S, Bergey G K, Anderson W S, Heck C, Liu C Y, Lee R W, Sadler T, Duckrow R B, Hirsch L J, Wharen R E, Tatum W, Srinivasan S, McKhann G M, Agostini M A, Alexopoulos A V., Jobst B C, Roberts D W, Salanova V, Witt T C, Cash S S, Cole A J, Worrell G A, Lundstrom B N, Edwards J C, Halford J J, Spencer D C, Ernst L, Skidmore C T, Sperling M R, Miller I, Geller E B, Berg M J, Fessler A J, Rutecki P, Goldman A M, Mizrahi E M, Gross R E, Shields D C, Schwartz T H, Labar D R, Fountain N B, Elias W J, Olejniczak P W, Villemarette-Pittman N R, Eisenschenk S, Roper S N, Boggs J G, Courtney T A, Sun F T, Seale C G, Miller K L, Skarpaas T L and Morrell M J 2020 Nine-year prospective efficacy and safety of brain-responsive neurostimulation for focal epilepsy Neurology 95 e1244-56

[3] Fisher R, Salanova V, Witt T, Worth R, Henry T, Gross R, Oommen K, Osorio I, Nazzaro J, Labar D, Kaplitt M, Sperling M, Sandok E, Neal J, Handforth A, Stern J, DeSalles A, Chung S, Shetter A, Bergen D, Bakay R, Henderson J, French J, Baltuch G, Rosenfeld W, Youkilis A, Marks W, Garcia P, Barbaro N, Fountain N, Bazil C, Goodman R, McKhann G, Krishnamurthy K B, Papavassiliou S, Epstein C, Pollard J, Tonder L, Grebin J, Coffey R, Graves N, Dichter M, Elias W, Francel P, Frysinger R, Graber K, Grant J, Heit G, Herman S, Kandula P, Kanner A, King J A, Kobylarz E, Lapp K, LaRoche S, Lippmann S, Maganti R, Mapstone T, Sabau D, Schrader L, Sharan A, Smith M, Treiman D, Wilkinson S, Wong S, Zangaladze A, Adderley S, Bridges B, Callanan M, Cordero D, Fields C, Johnson M, Kavalir M A, Kretschmar P, Macpherson C, Mancl K, Manley M, Marsh S, Montgomery J, Mundt P, Nekkalapu P P, Nikolov B, Palmer B, Perdue L, Randall A, Smith D, Smith L, Strybing K, Stott L, Taylor R, Thompson S, Timenova Z, Vogelsong B, Balbona V, Broshek D, Cahn-Weiner D, Clift L, Davidson M, et al 2010 Electrical stimulation of the anterior nucleus of thalamus for treatment of refractory epilepsy Epilepsia

[4] Salanova V, Sperling M R, Gross R E, Irwin C P, Vollhaber J A, Giftakis J E and Fisher R S 2021 The SANTÉ study at 10 years of follow-up: Effectiveness, safety, and sudden unexpected death in epilepsy Epilepsia 62 1306-17

[5] Ruoff L, Jarosiewicz B, Zak R, Tcheng T K, Neylan T C and Rao V R 2020 Sleep disruption is not observed with brainresponsive neurostimulation for epilepsy Epilepsia Open $\mathbf{5} 155-65$

[6] Voges B R, Schmitt F C, Hamel W, House P M, Kluge C, Moll C K E and Stodieck S R 2015 Deep brain stimulation of anterior nucleus thalami disrupts sleep in epilepsy patients Epilepsia 56 e99-103

[7] Bazil C W 2003 Epilepsy and sleep disturbance Epilepsy Behav. 4 39-45

[8] Piperidou C, Karlovasitou A, Triantafyllou N, Terzoudi A, Constantinidis T, Vadikolias K, Heliopoulos I, Vassilopoulos D and Balogiannis S 2008 Influence of sleep disturbance on quality of life of patients with epilepsy Seizure 17 588-94

[9] Moore J L, Carvalho D Z, St Louis E K and Bazil C 2021 Sleep and Epilepsy: a Focused Review of Pathophysiology, Clinical Syndromes, Co-morbidities, and Therapy Neurotherapeutics 18 170-80

[10] Alanis-Guevara I, Peña E, Corona T, López-Ayala T, López-Meza E and López-Gómez M 2005 Sleep disturbances, socioeconomic status, and seizure control as main predictors of quality of life in epilepsy Epilepsy Behav. 7 481-5

[11] Khatami R, Zutter D, Siegel A, Mathis J, Donati F and Bassetti C L 2006 Sleep-wake habits and disorders in a series of 100 adult epilepsy patients-A prospective study Seizure 15 299-306

[12] Staniszewska A, Mąka A, Religioni U and Olejniczak D 2017 Sleep disturbances among patients with epilepsy Neuropsychiatr. Dis. Treat. Volume 13 1797-803

[13] Durazzo T S, Spencer S S, Duckrow R B, Novotny E J, Spencer D D and Zaveri H P 2008 Temporal distributions of seizure occurrence from various epileptogenic regions Neurology

[14] Spencer D C, Sun F T, Brown S N, Jobst B C, Fountain N B, Wong V S S, Mirro E A and Quigg M 2016 Circadian and ultradian patterns of epileptiform discharges differ by seizure-onset location during long-term ambulatory intracranial monitoring Epilepsia 57 1495-502

[15] Hofstra W Ae and de Weerd A W 2009 The circadian rhythm and its interaction with human epilepsy: A review of literature Sleep Med. Rev.

[16] Dell K L, Payne D E, Kremen V, Maturana M I, Gerla V, Nejedly P, Worrell G A, Lenka L, Mivalt F, Boston R C, Brinkmann B H, D'Souza W, Burkitt A N, Grayden D B, Kuhlmann L, Freestone D R and Cook M J 2021 Seizure likelihood varies with day-today variations in sleep duration in patients with refractory focal epilepsy: A longitudinal electroencephalography investigation EClinicalMedicine

[17] PARISI P, BRUNI O, PIA VILLA M, VERROTTI A, MIANO S, LUCHETTI A and CURATOLO P 2010 The relationship between sleep and epilepsy: the effect on cognitive functioning in children Dev. Med. Child Neurol. 52 805-10

[18] Kwan P, Yu E, Leung H, Leon T and Mychaskiw M A 2009 Association of subjective anxiety, depression, and sleep disturbance with quality-of-life ratings in adults with epilepsy Epilepsia 50 1059-66

[19] Tröster A I, Meador K J, Irwin C P and Fisher R S 2017 Memory and mood outcomes after anterior thalamic stimulation for refractory partial epilepsy Seizure $\mathbf{4 5} 133-41$

[20] Weaver E M, Kapur V and Yueh B 2004 Polysomnography vs Self-reported Measures in Patients with Sleep Apnea Arch. Otolaryngol. - Head Neck Surg.

[21] Ghasemi P, Sahraee T and Mohammadi A 2018 Closed- and Open-loop Deep Brain Stimulation: Methods, Challenges, Current 
Kremen V, Brinkmann B H, Van Gompel J J, Stead M, St Louis E K and Worrell G A 2019 Automated unsupervised behavioral state classification using intracranial electrophysiology J. Neural Eng. 16026004

[23] Kremen V, Duque J J, Brinkmann B H, Berry B M, Kucewicz M T, Khadjevand F, Van Gompel J, Stead M, St Louis E K and Worrell G A 2017 Behavioral state classification in epileptic brain using intracranial electrophysiology J. Neural Eng. 14026001

[24] Chen Y, Gong C, Hao H, Guo Y, Xu S, Zhang Y, Yin G, Cao X, Yang A, Meng F, Ye J, Liu H, Zhang J, Sui Y and Li L 2019 Automatic Sleep Stage Classification Based on Subthalamic Local Field Potentials IEEE Trans. Neural Syst. Rehabil. Eng.

[25] Reed C M, Birch K G, Kamiński J, Sullivan S, Chung J M, Mamelak A N and Rutishauser U 2017 Automatic detection of periods of slow wave sleep based on intracranial depth electrode recordings $J$. Neurosci. Methods

[26] Balzekas I, Sladky V, Nejedly P, Brinkmann B H, Crepeau D, Mivalt F, Gregg N M, Attia T P, Marks V, Wheeler L P, Riccelli T E, Staab J P, Lundstrom B N, Miller K J, Van Gompel J, Kremen V, Croarkin P E and Worrell G A 2021 Invasive electrophysiology for circuit discovery and study of comorbid psychiatric disorders in patients with epilepsy: Challenges, opportunities, and novel technologies Front. Hum. Neurosci.

[27] Stanslaski S, Herron J, Chouinard T, Bourget D, Isaacson B, Kremen V, Opri E, Drew W, Brinkmann B H, Gunduz A, Adamski T, Worrell G A and Denison T 2018 A Chronically Implantable Neural Coprocessor for Investigating the Treatment of Neurological Disorders IEEE Trans. Biomed. Circuits Syst. 12 1230-45

[28] Kremen V, Brinkmann B H, Kim I, Guragain H, Nasseri M, Magee A L, Pal Attia T, Nejedly P, Sladky V, Nelson N, Chang S-Y, Herron J A, Adamski T, Baldassano S, Cimbalnik J, Vasoli V, Fehrmann E, Chouinard T, Patterson E E, Litt B, Stead M, Van Gompel J, Sturges B K, Jo H J, Crowe C M, Denison T and Worrell G A 2018 Integrating Brain Implants With Local and Distributed Computing Devices: A Next Generation Epilepsy Management System IEEE J. Transl. Eng. Heal. Med. 6 1-12

[29] Gilron R, Little S, Perrone R, Wilt R, de Hemptinne C, Yaroshinsky M S, Racine C A, Wang S S, Ostrem J L, Larson P S, Wang D D, Galifianakis N B, Bledsoe I O, San Luciano M, Dawes H E, Worrell G A, Kremen V, Borton D A, Denison T and Starr P A 2021 Long-term wireless streaming of neural recordings for circuit discovery and adaptive stimulation in individuals with Parkinson's disease Nat. Biotechnol.

[30] Chen R, Classen J, Gerloff C, Celnik P, Wassermann E M, Hallett M and Cohen L G 1997 Depression of motor cortex excitability by low-frequency transcranial magnetic stimulation Neurology

[31] Koubeissi M Z, Kahriman E, Syed T U, Miller J and Durand D M 2013 Low-frequency electrical stimulation of a fiber tract in temporal lobe epilepsy Ann. Neurol.

[32] Kile K B, Tian N and Durand D M 2010 Low frequency stimulation decreases seizure activity in a mutation model of epilepsy Epilepsia

[33] Fisher R, Salanova V, Witt T, Worth R, Henry T, Gross R, Oommen K, Osorio I, Nazzaro J, Labar D, Kaplitt M, Sperling M, Sandok E, Neal J, Handforth A, Stern J, DeSalles A, Chung S, Shetter A, Bergen D, Bakay R, Henderson J, French J, Baltuch G, Rosenfeld W, Youkilis A, Marks W, Garcia P, Barbaro N, Fountain N, Bazil C, Goodman R, McKhann G, Babu Krishnamurthy K, Papavassiliou S, Epstein C, Pollard J, Tonder L, Grebin J, Coffey R and Graves N 2010 Electrical stimulation of the anterior nucleus of thalamus for treatment of refractory epilepsy Epilepsia $\mathbf{5 1}$ 899-908

[34] Salanova V, Witt T, Worth R, Henry T R, Gross R E, Nazzaro J M, Labar D, Sperling M R, Sharan A, Sandok E, Handforth A, Stern J M, Chung S, Henderson J M, French J, Baltuch G, Rosenfeld W E, Garcia P, Barbaro N M, Fountain N B, Elias W J, Goodman R R, Pollard J R, Troster A I, Irwin C P, Lambrecht K, Graves N and Fisher R 2015 Long-term efficacy and safety of thalamic stimulation for drug-resistant partial epilepsy Neurology 84 1017-25

[35] Webb G I, Keogh E, Miikkulainen R, Miikkulainen R and Sebag M 2011 Naïve Bayes Encyclopedia of Machine Learning (Boston, MA: Springer US) pp 713-4

[36] Zhang H 2004 The optimality of Naive Bayes Proceedings of the Seventeenth International Florida Artificial Intelligence Research Society Conference, FLAIRS 2004

[37] Sladky V, Nejedly P, Mivalt F, Brinkmann B H, Kim I, St. Louis E K, Gregg N M, Lundstrom B N, Crowe C M, Attia T P, Crepeau D, Balzekas I, Marks V, Wheeler L P, Cimbalnik J, Cook M, Janca R, Sturges B K, Leyde K, Miller K J, Van Gompel J J, Denison T, Worrell G A and Kremen V 2021 Distributed Brain Co-Processor for Neurophysiologic Tracking and Adaptive Stimulation: Application to Drug Resistant Epilepsy bioRxiv 2021.03.08.434476

[38] Kremen V, Brinkmann B H, Kim I, Guragain H, Nasseri M, Magee A L, Pal Attia T, Nejedly P, Sladky V, Nelson N, Chang S Y, Herron J A, Adamski T, Baldassano S, Cimbalnik J, Vasoli V, Fehrmann E, Chouinard T, Patterson E E, Litt B, Stead M, Van Gompel J, Sturges B K, Jo H J, Crowe C M, Denison T and Worrell G A 2018 Integrating brain implants with local and distributed computing devices: A next generation epilepsy management system IEEE J. Transl. Eng. Heal. Med.

[39] Pal Attia T, Crepeau D, Kremen V, Nasseri M, Guragain H, Steele S W, Sladky V, Nejedly P, Mivalt F, Herron J, Stead M, Denison T, Worrell G A and Brinkmann B H 2021 Epilepsy Personal Assistant Device -A Mobile Platform for Brain State, Dense Behavioral and Physiology Tracking and Controlling Adaptive Stimulation Front. Neurol.

[40] Silber M H 2012 Staging sleep Sleep Med. Clin. 7 487-96

[41] Bower M R, Stead M, Bower R S, Kucewicz M T, Sulc V, Cimbalnik J, Brinkmann B H, Vasoli V M, St. Louis E K, Meyer F B, Marsh W R and Worrell G A 2015 Evidence for Consolidation of Neuronal Assemblies after Seizures in Humans J. Neurosci. 35 999-1010

[42] Lewis D D 1998 Naive(Bayes)at forty: The independence assumption in information retrieval Lecture Notes in Computer Science (including subseries Lecture Notes in Artificial Intelligence and Lecture Notes in Bioinformatics)

[43] Brinkmann B H, Bower M R, Stengel K A, Worrell G A and Stead M 2009 Large-scale electrophysiology: acquisition, compression, encryption, and storage of big data. J. Neurosci. Methods 180 185-92

[44] Torrey L and Shavlik J Transfer Learning Handbook of Research on Machine Learning Applications and Trends (IGI Global) pp $242-64$ 
medRxiv preprint doi: https://doi.org/10.1101/2021.08.10.21261645; this version posted August 12, 2021. The copyright holder for this preprint (which was not certified by peer review) is the author/funder, who has granted medRxiv a license to display the preprint in

All rights reserved. No reuse allowed without permission.

[45] Boëx C, Seeck M, Vulliémoz S, Rossetti A O, Staedler C, Spinelli L, Pegna A J, Pralong E, Villemure J-G, Foletti G and Pollo C 2011 Chronic deep brain stimulation in mesial temporal lobe epilepsy Seizure 20 485-90

[46] Bower M R, Kucewicz M T, St. Louis E K, Meyer F B, Marsh W R, Stead M and Worrell G A 2017 Reactivation of seizurerelated changes to interictal spike shape and synchrony during postseizure sleep in patients Epilepsia 58 94-104 
medRxiv preprint doi: https://doi.org/10.1101/2021.08.10.21261645; this version posted August 12, 2021. The copyright holder for this preprint (which was not certified by peer review) is the author/funder, who has granted medRxiv a license to display the preprint in

All rights reserved. No reuse allowed without permission.

\section{Supplementary Materials}

\section{Clinical Information: Neurophysiologically-Based Brain State Tracking \& Modulation in Focal Epilepsy (NIH UH3 NS095495 \& FDA IDE-G180224)}

We consented 6 patients and implanted 4 patients with drug resistant temporal lobe epilepsy (TLE) as part of the NIH Brain Initiative Neurophysiologically-Based Brain State Tracking \& Modulation in Focal Epilepsy. Patients are implanted with investigational Medtronic Summit $\mathrm{RC}+\mathrm{S}^{\mathrm{TM}}$ neural sense and stimulation device with bilateral anterior nucleus of thalamus (ANT) and hippocampus (HPC) electrodes. The epilepsy patient assistant (EPA) application running on a hand-held device provides integration of wearable and implantable devices. The FDA IDE protocol investigates electrical brain stimulation (EBS) paradigms, including low frequency $(2 \& 7 \mathrm{~Hz})$ and high frequency $(100 \& 145 \mathrm{~Hz})$ stimulation, seizure detection and forecasting, behavioral state tracking, and adaptive EBS control. Supplementary Figure 1 shows a schematic of the implanted system and co-registration of implanted electrodes.
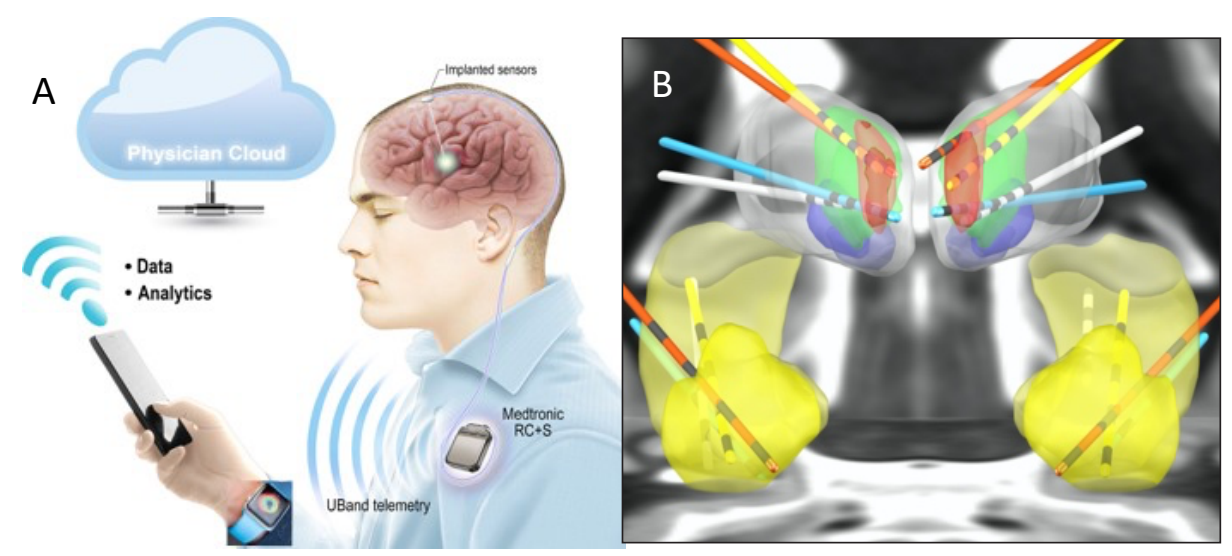

Supplementary Figure 1. Epilepsy Management System: A) Implantable neural sensing and stimulating (RC+S) device with bi-directional communication to off-the- body computing enabling machine learning analytics. The system integrates $\mathrm{RC}+\mathrm{S}$, wearable sensors (e.g., watch), handheld computing device with cloud computing environment. B) Coregistration of the bilateral ANT and HPC leads in the four implanted patients. The anterior nucleus of thalamus (ANT red) and hippocampus (HPC light yellow) and amygdala (AMG yellow). 
medRxiv preprint doi: https://doi.org/10.1101/2021.08.10.21261645; this version posted August 12, 2021. The copyright holder for this preprint (which was not certified by peer review) is the author/funder, who has granted medRxiv a license to display the preprint in perpetuity.

All rights reserved. No reuse allowed without permission.

Supplementary Table S1. Setup of EBS parameters for all human subjects involved in the study during three consecutive nights (Day 13) when the iEEG data were acquired simultaneously with PSG data to create the gold standard human expert sleep scoring. The iEEG data were acquired from Hippocampus (HPC). Electrical brain stimulation was applied bilaterally in the anterior nucleus of thalamus (ANT). Periodic cycling between different EBS setups, that are given by frequency (f), stimulation current (I) and pulse width (PW), was applied to all subjects.

\begin{tabular}{|c|c|c|c|c|c|c|c|c|c|}
\hline & \multicolumn{3}{|c|}{ Day 1 } & \multicolumn{3}{c|}{ Day 2 } & \multicolumn{3}{c|}{ Day 3 } \\
\hline & $\mathrm{f} / \mathrm{Hz}$ & $\mathrm{I} / \mathrm{mA}$ & $\mathrm{PW} / \mathrm{us}$ & $\mathrm{f} / \mathrm{Hz}$ & $\mathrm{I} / \mathrm{mA}$ & $\mathrm{PW} / \mathrm{us}$ & $\mathrm{f} / \mathrm{Hz}$ & $\mathrm{I} / \mathrm{mA}$ & $\mathrm{PW} / \mathrm{us}$ \\
\hline $\mathrm{H} 1$ & - & - & - & $7 ; 100$ & 3 & 90 & $2 ; 100$ & 3 & 90 \\
\hline $\mathrm{H} 2$ & 2 & 6 & 200 & $2 ; 7$ & $5 ; 6$ & 200 & 145 & 4 & 200 \\
\hline $\mathrm{H} 3$ & 2 & 6 & 200 & $7 ; 145$ & 4 & 200 & $2 ; 7$ & 5 & 200 \\
\hline $\mathrm{H} 4$ & 145 & 2 & 200 & 2 & 6 & 200 & 7 & 6 & 200 \\
\hline
\end{tabular}

Supplementary Table S2. Number of 30-second iEEG epochs collected, EBS parameters, and sleep stage across the three hospital nights. Only epochs with data rate higher than $85 \%$ are included.

\begin{tabular}{|c|c|c|c|c|c|c|c|c|c|c|c|c|c|c|c|c|}
\hline & & \multicolumn{5}{|c|}{ Night 1} & \multicolumn{5}{|c|}{ Night 2} & \multicolumn{5}{|c|}{ Night 3} \\
\hline & $\begin{array}{l}\text { Stim } \\
\text { Mode }\end{array}$ & W & N1 & N2 & N3 & REM & W & N1 & $\mathrm{N} 2$ & N3 & REM & W & N1 & $\mathrm{N} 2$ & N3 & REM \\
\hline \multirow{5}{*}{ 포 } & No stim & 421 & 14 & 291 & 266 & 168 & 277 & 6 & 119 & 102 & 91 & 135 & 12 & 75 & 123 & 40 \\
\hline & $2 \mathrm{~Hz}$ & - & - & - & - & - & - & - & - & - & - & 48 & 2 & 34 & 50 & 53 \\
\hline & $7 \mathrm{~Hz}$ & - & - & - & - & - & 148 & 3 & 82 & 30 & 3 & - & - & - & - & - \\
\hline & $100 \mathrm{~Hz}$ & - & - & - & - & - & 93 & 5 & 74 & 75 & 38 & 103 & 1 & 46 & 33 & 22 \\
\hline & All & 421 & 14 & 291 & 266 & 168 & 518 & 14 & 275 & 207 & 132 & 286 & 15 & 155 & 211 & 115 \\
\hline \multirow{5}{*}{$\underset{I}{I}$} & No stim & - & - & - & - & - & 320 & 19 & 113 & 63 & 22 & 72 & 7 & 268 & 34 & 54 \\
\hline & $2 \mathrm{~Hz}$ & - & - & - & - & - & 115 & 12 & 49 & 71 & 5 & - & - & - & - & - \\
\hline & $7 \mathrm{~Hz}$ & - & - & - & - & - & 122 & 1 & 69 & 35 & 17 & - & - & - & - & - \\
\hline & $145 \mathrm{~Hz}$ & - & - & - & - & - & - & - & - & - & - & 89 & 32 & 347 & 33 & 60 \\
\hline & All & - & - & - & - & - & $\mathbf{5 5 7}$ & 32 & 231 & 169 & 44 & 161 & 39 & 615 & 67 & 114 \\
\hline \multirow{5}{*}{$\frac{m}{I}$} & No stim & 447 & 16 & 296 & 83 & 180 & 171 & 8 & 46 & 25 & 25 & 327 & 14 & 98 & 42 & - \\
\hline & $2 \mathrm{~Hz}$ & 145 & 16 & 282 & 107 & 117 & - & - & - & - & - & 45 & 14 & 58 & 26 & - \\
\hline & $7 \mathrm{~Hz}$ & - & - & - & - & - & 104 & - & 24 & 24 & 23 & 30 & 6 & 80 & 6 & - \\
\hline & $145 \mathrm{~Hz}$ & - & - & - & - & - & 100 & 1 & 25 & 8 & 10 & - & - & - & - & - \\
\hline & All & 592 & 32 & 578 & 190 & 297 & 375 & 9 & 115 & 57 & 58 & 402 & 34 & 236 & 74 & - \\
\hline \multirow{5}{*}{$\underset{I}{I}$} & No stim & 71 & 42 & 183 & 62 & 59 & 90 & 67 & 220 & 40 & 35 & - & - & - & - & - \\
\hline & $2 \mathrm{~Hz}$ & - & - & - & - & - & 142 & 144 & 427 & 72 & 43 & - & - & - & - & - \\
\hline & $7 \mathrm{~Hz}$ & - & - & - & - & - & - & - & - & - & - & - & - & - & - & - \\
\hline & $145 \mathrm{~Hz}$ & 111 & 76 & 370 & 120 & 86 & - & - & - & - & - & - & - & - & - & - \\
\hline & All & 182 & 118 & 553 & 182 & 145 & 232 & 211 & 647 & 112 & 78 & - & - & - & - & - \\
\hline
\end{tabular}


medRxiv preprint doi: https://doi.org/10.1101/2021.08.10.21261645; this version posted August 12, 2021. The copyright holder for this preprint (which was not certified by peer review) is the author/funder, who has granted medRxiv a license to display the preprint in perpetuity.

All rights reserved. No reuse allowed without permission.

Supplementary Table S3. Results of automated behavioral sleep state classification (F1-score) into Awake, REM, N2, N3, sleep categories for all subjects under various settings of electrical brain stimulation (EBS) in anterior nucleus of thalamus (ANT). The classification score is reported for the general NREM category comprising N2 \& N3 as well. The feasibility of automated sleep classification using a single channel iEEG data recorded from HPC was performed using no EBS data. The classifier was trained using only the first night of no EBS data and pseudo-prospectively (PP) tested using the $2^{\text {nd }}$ and $3^{\text {rd }}$ night of no EBS data. The classifiers for different stimulation setups utilize transfer learning (TL) when training the classifiers using no EBS data and testing on data acquired under corresponding EBS setups. The experiment was replicated twice for the 2 \& $7 \mathrm{~Hz}$ stimulation data, with and without band power cancelling, as introduced in "Cancelling of Band Bower at Stimulation Frequencies". Moreover, $20 \%$ cross-validation testing (CV) proportionally sampled across all classification categories was performed for the high frequency electrical brain stimulation setups. Values marked by * were achieved using less than 10 samples and therefore are not considered valid.

\begin{tabular}{|c|c|c|c|c|c|c|c|c|c|c|}
\hline EBS Setup & $\begin{array}{c}\text { Validation } \\
\text { Method }\end{array}$ & $\begin{array}{c}\text { Band } \\
\text { Power } \\
\text { Cancelling } \\
\end{array}$ & Subject & Awake & REM & N2 & N3 & NREM & All & All $_{\text {NREM }}$ \\
\hline \multirow{15}{*}{ No EBS } & \multirow{15}{*}{ PP } & \multirow{5}{*}{ No } & H1 & .946 & .703 & .519 & .723 & .923 & .800 & .910 \\
\hline & & & $\mathrm{H} 2$ & .848 & .660 & .740 & .338 & .944 & .691 & .893 \\
\hline & & & H3 & .759 & .497 & .547 & .563 & .803 & .669 & .753 \\
\hline & & & H4 & .798 & .763 & .621 & .763 & .924 & .719 & .890 \\
\hline & & & Average & .838 & .656 & .607 & .597 & .899 & .720 & .862 \\
\hline & & \multirow{5}{*}{$\begin{array}{l}\text { Yes } \\
2 \mathrm{~Hz}\end{array}$} & $\mathrm{H1}$ & .941 & .736 & .415 & .700 & .923 & .775 & .910 \\
\hline & & & $\mathrm{H} 2$ & .863 & .712 & .720 & .196 & .944 & .691 & .896 \\
\hline & & & H3 & .677 & .323 & .074 & .488 & .748 & .654 & .736 \\
\hline & & & H4 & .246 & .000 & .265 & .204 & .803 & .576 & .790 \\
\hline & & & Average & .682 & .443 & .369 & .397 & .855 & .674 & .833 \\
\hline & & \multirow{5}{*}{$\begin{array}{l}\text { Yes } \\
7 \mathrm{~Hz}\end{array}$} & H1 & .934 & .613 & .333 & .709 & .935 & .779 & .904 \\
\hline & & & $\mathrm{H} 2$ & .844 & .712 & .774 & .360 & .952 & .733 & .909 \\
\hline & & & H3 & .732 & .503 & .597 & .613 & .812 & .666 & .744 \\
\hline & & & H4 & .829 & .776 & .533 & .605 & .899 & .704 & .879 \\
\hline & & & Average & .835 & .651 & .484 & .572 & .900 & .721 & .859 \\
\hline \multirow{10}{*}{$2 \mathrm{~Hz}$} & \multirow{10}{*}{$\mathrm{TL}$} & \multirow{5}{*}{ No } & H1 & .991 & .753 & .455 & .750 & .897 & .765 & .892 \\
\hline & & & $\mathrm{H} 2$ & .960 & .714 & .552 & .440 & .960 & .755 & .940 \\
\hline & & & H3 & .383 & .544 & .804 & .714 & .920 & .676 & .763 \\
\hline & & & $\mathrm{H} 4$ & .696 & .491 & .169 & .522 & .788 & .480 & .781 \\
\hline & & & Average & .758 & .626 & .495 & .607 & .891 & .669 & .844 \\
\hline & & \multirow{5}{*}{$\begin{array}{l}\text { Yes } \\
2 \mathrm{~Hz}\end{array}$} & H1 & .991 & .848 & .364 & .721 & .932 & .789 & .931 \\
\hline & & & $\mathrm{H} 2$ & .955 & .727 & .437 & .442 & .932 & .743 & .936 \\
\hline & & & H3 & .783 & .426 & .442 & .712 & .883 & .683 & .817 \\
\hline & & & $\mathrm{H} 4$ & .286 & .111 & .127 & .072 & .763 & .525 & .768 \\
\hline & & & Average & .754 & .528 & .343 & .487 & .878 & .685 & .863 \\
\hline \multirow{10}{*}{$7 \mathrm{~Hz}$} & \multirow{10}{*}{$\mathrm{TL}$} & \multirow{5}{*}{ No } & H1 & .977 & $.100^{*}$ & .250 & .635 & .929 & .756 & .926 \\
\hline & & & $\mathrm{H} 2$ & .964 & .643 & .446 & .295 & .973 & .787 & .957 \\
\hline & & & H3 & .818 & .700 & .774 & .750 & .879 & .807 & .845 \\
\hline & & & $\mathrm{H} 4$ & - & - & - & - & - & - & - \\
\hline & & & Average & .920 & .672 & .490 & .560 & .927 & .783 & .909 \\
\hline & & \multirow{5}{*}{$\begin{array}{l}\text { Yes } \\
7 \mathrm{hz}\end{array}$} & H1 & .974 & $.353^{*}$ & .444 & .690 & .949 & .815 & .941 \\
\hline & & & $\mathrm{H} 2$ & .976 & .914 & .396 & .491 & .978 & .829 & .973 \\
\hline & & & H3 & .870 & .903 & .886 & .810 & .935 & .884 & .918 \\
\hline & & & $\mathrm{H} 4$ & - & - & - & - & - & - & - \\
\hline & & & Average & .940 & .909 & .575 & .664 & .954 & .843 & .944 \\
\hline
\end{tabular}


medRxiv preprint doi: https://doi.org/10.1101/2021.08.10.21261645; this version posted August 12, 2021. The copyright holder for this preprint (which was not certified by peer review) is the author/funder, who has granted medRxiv a license to display the preprint in perpetuity.

All rights reserved. No reuse allowed without permission.

\begin{tabular}{|c|c|c|c|c|c|c|c|c|c|c|}
\hline \multirow{10}{*}{$\begin{array}{c}\text { High } \\
\text { Frequency } \\
\text { (100 \& } \\
145 \mathrm{~Hz})\end{array}$} & \multirow{5}{*}{$\mathrm{TL}$} & \multirow{5}{*}{ No } & H1 & .948 & .767 & .381 & .689 & .950 & .768 & .920 \\
\hline & & & $\mathrm{H} 2$ & .506 & .667 & .522 & .250 & .896 & .658 & .814 \\
\hline & & & H3 & .458 & $.353^{*}$ & .478 & $.571^{*}$ & .761 & .574 & .652 \\
\hline & & & $\mathrm{H} 4$ & .774 & .800 & .841 & .673 & .971 & .857 & .939 \\
\hline & & & Average & .672 & .745 & .556 & .537 & .895 & .714 & .831 \\
\hline & \multirow{5}{*}{$\mathrm{CV}$} & \multirow{5}{*}{ No } & H1 & .970 & .894 & .564 & .771 & .987 & .850 & .975 \\
\hline & & & $\mathrm{H} 2$ & .703 & .772 & .613 & .176 & .944 & .772 & .902 \\
\hline & & & H3 & .899 & $.716^{*}$ & .693 & $.000 *$ & .857 & .826 & .899 \\
\hline & & & $\mathrm{H} 4$ & .767 & .702 & .926 & .725 & .975 & .895 & .926 \\
\hline & & & Average & .835 & .789 & .699 & .418 & .941 & .836 & .926 \\
\hline
\end{tabular}

